\title{
Interview with Tata Consultancy Services - Media and Entertainment Practice
}

\section{Edward Altman}

is the Practice Director of Tata Consultancy Services (TCS) America's Media and Entertainment Practice responsible for building this new industry practice for TCS. Prior to entering the consulting business, Ed spent six years in the entertainment industry most recently serving as the Chief Information Officer of Metro-Goldwyn-Mayer. Ed is a member of the Society for Information Management (SIM) and served as the Chairman of the Board of Directors of SIM's Southern California Chapter. Ed is also a member of the Information Systems Associates Program of the Anderson Graduate School of Business Administration at UCLA and served as its Chairman for three years. Ed received his BS and MS degrees in Mathematics/Computer Science from the University of Michigan.

Keywords: DRM, piracy, IT services, Web 2.0, digital assets, social networking

Abstract Tata Consultancy Services (TCS) is an IT services, business solutions and outsourcing organization that delivers real results to global businesses, ensuring a level of certainty no other firm can match. TCS offers a consulting-led, integrated portfolio of Business, IT and IT-enabled services delivered through its unique Global Network Delivery Model. TCS has over 100,000 of the world's best trained IT and business consultants in 47 countries. The company generated consolidated revenues of US $\$ 4.3 \mathrm{bn}$ for fiscal year ended 31 March 2007. More than 35 of the largest Media and Entertainment companies in the world trust TCS in their quest for certainty in an extremely volatile industry jostling with evolving market forces - Digitization, Convergence and their effects on new media forms. TCS' wide ranging experience spans the entire content value chain - from creation to distribution, across each of the sub-segments (print and publishing, filmed entertainment, broadcast and cable networks, music, advertising and new media), and from IT services to Digital Media platforms across the Globe.

Journal of Digital Asset Management (2008) 4, 13-22. doi:10.1057/dam.2008.2

Edward Altman

Media and Entertainment Tata Consultancy Services (TCS) America.

E-mail: edward.altman@ tcs.com
MM: So, whom do we have on the telephone here?

EA: Let's quickly go around. We've got Ed Altman, the practice head; Sherra Pierre March

— TCS, Media Solution Strategist, based out of New York City; Shrikant Pathak, Practice Director, Media Entertainment, TCS Mumbai; Sanjeev Goyal - Solutions Lead, Media and Entertainment Practice, Mumbai, India; Anand Narayanan, Media and Entertainment Practice, TCS Burbank; Srinivas G - Solutions Lead , Media and Entertainment Practice, TCS Burbank; John Dubrawski, Business Development, TCS Burbank.

MM: I'd like to open up by giving you a preview in terms of the kinds of questions that I'd like to have you address. That is the state of DAM in publishing and media.
What kinds of things, in terms of most media and publishing and entertainment firms today... What do they mostly have in place now?

Then beyond that, more forward-looking, what sort of business strategies are publishes, media firms, entertainment firms... How do they see DAM as a strategy? A way of marshaling their resources for competitive advantage?

Hopefully, this will lead into - not necessarily in this order... But nonetheless, lead into the notion of supply chains? Perhaps we can start with a basic definition of a supply chain, and then apply that to a content supply chain.

Then the next piece that I'd like to get into is this notion of social media. Media that's related to either user-generated content or 
user-generated additions to professionally generated content. Then if we have time, what are some of the transformational applications in the DAM and/or publishing space that you envision?

Then finally, if we get to this, the servicedelivery methodologies. This really gets to the management control frameworks like CMMI or other sorts of process quality-control frameworks.

Who would like to start with the state of publishing media entertainment in terms of key developments in IT service delivery and/or DAM?

EA: Sherra. Why don't you lay the groundwork for it?

SPM: This is Sherra Pierre-March - Media \& Entertainment Practice, TCS. There are some common themes, I believe, among publishers. These themes include looking forward to XML centric publishing solutions that allow them to manage the content as far up the ecosystem as possible. As we talk about the ecosystem, we talk about creation and management and delivery of the content.

I think publishers are also looking for the next-generation of DAM, as it relates to supporting an XML centric publishing solution. I think they're looking to integrate into a wider content management solution, layers of workflow. Layers of web-content management. Layers of integration with rights systems whether they be business, systems or digital rights.

Better metadata integration. I think we see one good example of that obviously with the introduction of Documentum's XML database solution. That's their new version that of course we all know about. And the success of Mark Logic, and the role that it plays in the context of traditional DAM.

The other things that we're seeing are obviously the effect on supply chains, and what supply chains are today for publishers. And as we move into a true digital-to-digital solution, how is the media lifecycle being transformed, as we shift from this analog-to-digital, or hard-to-usedigital to used-by-anybody digital? I think that publishers are trying to solve that.

That then leads into their ability to do dynamic fulfillment and distribution to multichanneled opportunities. So now publishers,
I believe, are looking for those kinds of solutions that say, "Hey. How do we get our content into one black box," so to speak. "To have that content be transformed and converted for the appropriate channel opportunity?"

Whether it's a podcast or move-out platform. Whether the content needs to be crawled by Google or Yahoo, et cetera.

I think the last piece that we're seeing in terms of trends for publishers is this whole notion of redefining product. As an example, the impact of Web 2.0 technologies to include widgets and syndication of content. The addition of ad serving. The addition of social networking. And the impact on content, and how people consume and understand content and want to interact with content.

I think there are about five things that I just went through that are at the top of the list for publishers. And this goes across the board of educational, newspapers and trade magazines.

I just recently read a great article in the New York Times about widgets, and how much newspapers were beginning to develop their own widgets. This is becoming a priority for them, in terms of how they want folks to interact with their content.

MM: Great.

In terms of the IT service-management or service-delivery, what sort of developments and/or challenges and opportunities have now surfaced and are generally top-of-mind with media, entertainment and publishing firms? SP: This is Shrikant Pathak from TCS Mumbai.

I think there are three areas in which the publishing and media firms see the driver happening. One is to monetize the content assets. Second is to create production efficiencies. And third is to effectively compete with the new generation content and media firms.

There are different aspects that come in if you take, for instance, monetizing assets. For book publishing, many of their assets are sitting in a form which is not effectively usable in the digital world.

So monetizing of the assets involves its own investment and asset conversion to digital form. The same thing applies to even Hollywood companies, as well. So that is one side of the drive which is happening in the IT services. Converting assets to digital form. 
In the creation of production efficiencies, you have things happening on the IT/IS side. And you have things happening on the production floor side. So both aspects are being driven. IT side has been probably happening on a more conventional basis. One difference that we see in the media and entertainment world vis-à-vis other industry segment is media entertainment has grown a lot more by mergers and acquisitions. It has a much more diversified set of IT assets that need to be now perhaps consolidated. Maybe made into an enterpriselevel IT and IS systems.

That's beginning to happen in the bookpublishing segment as well. In the bookpublishing side, the drive is also from the point of view of creating efficiencies to keep the costs down. That's the segment which is hurting more than others.

When we talk about competing with newgeneration media and content forms, many of these companies have begun to look at Google and the likes of them that are in some ways competitors for their segment. Therefore there is another drive happening. To see how you can effectively leverage the paradigm and collaborate with those folks rather than compete with them - and build upon what's becoming available, rather than fend it off and stay away.

Some firms have tried the collaboration route, while some firms have gone ahead and started legal proceedings against the new media firms.

But I think you've seen the change in the companies' thinking processes. They're saying, "Well, this is something that is a momentum of the industry. It's something that you can't really stop from happening." So how can we effectively leverage that?

I see the IT and IS services management in these three areas [coming in].

EA: This is Ed Altman. I would like to add to that. From the IT side, there's always been a question of the CIO being a member of a senior management team and driving the business, or the CIO just managing the plumbing in the back office, and buying the breakfast and lunch. But for God's sake - you never invite a CIO to dinner.

If you look at what's going on now - the elevation of a CIO from if they were in that back office exclusively, that's really changing very, very quickly in many of the publishing companies. They are really beginning to be an integral part of driving these digital media strategies for pretty much all the obvious reasons.

That role within the publishing industry is literally changing very, very quickly. We see that a lot, certainly in the last 6-12 months.

SPM: This is Sherra Pierre-March. I just wanted to point out five things, as well, from an IT operational perspective. I think there are five main things that IT's challenged with.

One is the cost of creation, and the mechanisms and solutions to support that. Second is the cost of distribution. Third is the proliferation. Fourth is available bandwidth. And fifth, I believe, is demand for personalization.

Those are the five things that I think in terms of managing, what this infrastructure needs to ultimately support as companies embrace this notion of "liquid media..." This ability for this media to exist and be everywhere and be everything for everyone.

I think those may be the five things, and I'm sure there are more to come. But those are the five that stick at the top of my mind.

MM: Sure. I'm purposely just holding back, in the event that there are any other individuals like Anand or whatever that would like to chime in here before I move to the next level. SG: It's Sanjeev Goyal from TCS Mumbai.

I just wanted to add on actually what Shrikant said. I'm talking about the IT services layer. Digital Asset Management, we have seen traditionally used for the IT function. Not necessarily for the IT function, because most of the DAM implementation we've seen in the past for the IT organization.

I think now it's becoming more of the business function. That's the kind of change we are seeing. If not led by the traditional IT organization, companies are creating a new IT organization. They're taking care of DAM business.

Especially on the revenue-generation side. MM: If I understood you right, IT has undergone a transition or transformation from a traditional kind of support role to more driving of a business or business function. And that new IT organization that's really driving the business function has now incorporated DAM as part of its capability.

SG: Absolutely. That's right. 
And I think that every company's doing that. But those are the kinds of plans that we're seeing in most of the companies.

MM: Great.

One of the things that - in essence, everyone has referenced here is that as more and more of the consumers for media, entertainment and publishing firms... As more of these consumers derive a larger and larger portion of their value from media, entertainment and television firms from the online presence... Be they the web, the mobile, and maybe even kiosks or other sorts of points of presence...

As consumers begin to relate to media, entertainment and publishing groups through some sort of online interactive means, not just the content but the whole interaction model and the whole technical infrastructure becomes central to the company's brand.

Specifically, what does this mean to me as a human being and as a consumer? Et cetera.

So as the technology has become more integral to the consumer's experience... and therefore, the brand... and then by extension, my loyalty and my willingness to do business with the firm in the future...

We've talked about things like search optimization. We've talked about liquid forms of media and various kinds of devices and so on. Doesn't this really make the CIO or whoever's marshaling all of those resources and aligning them with corporate objectives? Doesn't that make the CIO the de facto owner and driver of the digital brand?

And does this set up a tension between the traditional marketing and sales part of the house that knows how to sell books or magazines, but doesn't necessarily understand the technical intricacies of their digital infrastructure, and therefore the digital brand?

EA: Michael, this is Ed Altman. I would use a little bit different words than what you did.

MM: Please.

EA: I would describe it this way.

I think that the evolution... And this has really begun to occur in the last 12 months. This is not something that started much before that.

So I'm also saying this is a work in process. This is a trend that is emerging as we speak.

The way I would look at it is that this whole industry has been hit over the head by the change in consumer behavior and consumer attitudes in terms of the selection and use of media, and the decision process of how they go about choosing a movie or a book or a newspaper and article.

Yes, it's been the social networking. Web 2.0. What we've learned from the MySpace and so forth. But as that phenomenon has occurred, I think there are two things.

One - the publishers realize that they want to then use those kinds of tools and techniques and ways of thinking to interact with their traditional constituency. But also, that traditional constituency is saying, "This is how I hook up. Whether I'm dating or buying a book or getting a referral or whatever. This is now how I want to interact with you."

Then on the flip side, you can see book publishers or education publishers as a great example saying, "Okay. We publish education books for the 3rd grade or for the sophomore year in college. Perhaps we should now be making some of those available in an ondemand type world. Maybe they should be able to print them. Maybe they should just be able to download them to their e-book reader."

It's gone further than that. If you take a classroom situation for the 4th grade, it's not just providing content, but it's providing a social environment - which has always been there. It just hasn't had an electronic platform whether it's PC-based or phone-based or whatever - that the teacher and the students would interact with the content for the lessons on how to learn your ABCs.

Or a different environment with the same kind of tools and "social networking," in terms of the professor. And in your calculus class, as a sophomore in college. The interaction over the interplay of the students, the teacher and the content itself. In the $3 \mathrm{rd}$ or 4 th grade, it might be taking classes, and the publisher providing training or testing.

Integrated with this whole process, and based on how you do on the testing, you're then automatically fed certain chapters or whatever it is - subsets - of the book. So it's really an interaction that's going on there between the consumer and the publisher of content.

As this has evolved... I really don't want to say that the CIO is leading the charge. It's just that the CIO is now a needed and respected 
member of the team within the company that's leading the charge. Whereas before, it was just, "Do your accounting system or your distribution system." Now in the area of more integrating the product and revenue generation like a consumer, that CIO is a key member of the team that's led by the president of the publishing division or the CEO of the company, of the marketing and sales.

Yes. There may be some animosities because they remember five years ago when the CIO couldn't even do blah-blah-blah. But I think as they're working through these cultural changes, that $\mathrm{CIO}$ is needed and has proven themselves to be a key member of the team. He's really part of that team that's leading this charge.

AN: If I may add to what Ed said. This is Anand Narayanan.

Regarding your statement, Michael, about whether CIOs are now becoming the primary owners of the digital brand. This leads back to the transformation that Sanjeev was talking about in the IT department's role - and therefore in the CIO's role. From more of a back office operation to a more leading the charge. Or embracing the change in the front office.

It's also - I believe, as you look at the market value chain of many of these companies - they move from $\mathrm{B} 2 \mathrm{~B}$ or $\mathrm{B} 2 \mathrm{~B} 2 \mathrm{C}$ to embracing elements of $\mathrm{B} 2 \mathrm{C}$ directly. They're now having to deal more with end-consumers than they ever had in the past.

What does this mean? This means that the role of the CTO who was deciding the technology elements for the market space, and the role of the CIO who was looking at back office operational IT are now beginning to merge. And we're seeing a pattern of this, where the CIO is now given a seat on the important decision making table in the organization. When they're deciding on market strategy or distribution strategy. Even price point and consumer experiences.

In that sense, the $\mathrm{CIO}$ - while probably not the lead or the caretaker of the digital brand is a very important member and a key stakeholder in the theme that decides the digital brand.

EA: This is Ed Altman. There's a major business change that's going on in general. When you think of media, you can't help but think of a direct-to-consumer. Consumers buy movies. Consumers buy books.

The reality is on the business side, almost across the board and across the sub-segments whether it's Hollywood or publishing newspapers or whatever... It's a B2B business. They deal with a distributor. Whether it's an AMC, a GCC or a newsstand where you go to get your New York Times or LA Times. These have all been really great B2B businesses.

The lack of the direct consumer interaction and the lack of the direct consumer data has been the way all of these businesses have grown up. But when they look at their businesses today, they are all getting direct-to-consumer.

If you look at what News [inaudible] and NBC are doing with [Hulu] — that is an effort directly dealing with the consumer. If you look at the book-publishing industry, they're beginning now to deal directly with the consumer.

That's probably one of the most fundamental changes - or the most fundamental change that's going on in reaction to the social networking. The online acquisition and demand for content. Hence, a lot of these changes that we're talking about.

SPM: This is Sherra Pierre March. It's an interesting question. You know? Who's the de facto owners, as it relates to brand development and product development, in this particular century, I guess.

I just wanted to step back a little bit to answer that question. I think that as media companies transform themselves, and they try to now satisfy the quest and the thirst of their consumers... I think that they're all struggling with organizational strategies. And in stepping back a little bit, I want to talk a little bit about what it takes to build that business.

There are four or five key toolsets that are there. You have your technology, your finances, your marketing and sales, and your operations as it relates to HR, and what I call "traditional IT." Is your payroll working? Are all your back office systems working? And legal.

The question is, "Who ultimately owns those tools now, as it relates to product development?"

In the experience, I am seeing shifts. I'm seeing where CTOs are being brought into place to really drive product development. I'm seeing where CIOs in certain circumstances are 
being left with the supporting back office systems. Where DAM will play a very important role.

DAM then becomes now a core critical app, I guess in the same way that e-mail has become a core critical app over the last 10 to 15 years. I can see that absolutely happening.

I think when it comes to the absolute product development and the folks who decide what these business models are, there's a new generation of technologists who bridge the gap of what the back end services need to produce. So that is inclusive of DAM and digital rights and workflow systems and so forth.

They bridge that as to what the actual product should be.

In the same way that we saw interactive groups come into play when dot-coms first became a reality... There really is a new generation of marketing people and business people who are very technology-savvy. They totally understand what these products look like, and they understand the complete model that supports the business of getting that product out there, and making sure they have a successful brand.

So they understand the ad-serving. They understand the e-commerce. They understand the marketing. They understand the placement of Web 2.0 services. And it's a whole lingo - a whole other reality.

So I struggle with the question of the $\mathrm{CIO}$ becoming the de facto. I think I agree with Ed on that. I don't know if that's necessarily true.

But I do know that there's more [inaudible] in all strategies that now need to be put into place for media and entertainment companies now, as they transform and transition their content and their product models.

MM: Great.

This is brilliant. This has worked out better than I had hoped. And I had pretty high hopes. So, good work.

One of the things - kind of a meta-theme of our entire conversation here - has been shifts. Transition shifts - if not a transformation in basic consumption of media. Part of that was that we have a whole new generation of media consumers that have different expectations, different use patterns and almost a different relationship to the whole media-based experience.
One way of talking about that that I've begun to use is to speak of the people that are 30 years or younger today as not just having two hands, but actually having a third digital hand.

Somehow they have developed in their psychology and in their cognitive process they've almost internalized the entirety of the web, and the whole notion of being online is a $24 \times 7$ experience for them. Especially when you add in things like instant messaging and mobile phones and all that stuff.

As we start to think through and start to think about how media companies - especially the entertainment firms... Because that younger constituency is the primary driver for entertainment... What are some of the things that you've heard from your clients and/or what are some of the things that you're seeing in the industry that indicate or can give greater shape or meaning to this change in media consumption.

EA: This is Ed Altman. I think the Number 1 thing when you see change... There's maybe a tad of sarcasm here, but you must realize that in the legacy side of every one of these businesses, the numbers are heading south. It's not just the music industry, any more. That's just common knowledge. But obviously, the newspaper business. Ad circulation, there's no secret that in Hollywood the revenue and profits generated from DVD sales was not hockey-sticking up anymore — so people are suddenly getting worried and even panicking.

MM: You will.

EA: Okay. I will. I don't even know if it's a bad one. But anyway, it's flatting and it's not even going down.

The viewership in televisions has really been shrinking for 10 or 15 years. Literally, three days ago, Nielsen is now using... And the data is out there... Where they're publishing DVR. There's even new data out there on television shows the number of people that watch a television show live.

I believe if you watch it within three days, they're able to say that you watched it on a DVR. The data... I'm just digressing for a second, but it's a great example.

For scripted shows, it shows something like a 13 per cent uptake in people watching from a DVR. If it's an unscripted show or if it's of 
a competitive nature, people aren't really looking to the DVR, because it's then like a sporting event, everybody in your social network knows the results of what's going on, then the value of watching it later diminishes.

So the value of a DVR on an unscripted show is way less than on a scripted show. MM: So Ed, if I could just punctuate that for a moment. You're saying that as the TiVo and PDR kind of devices continue to propagate into the American home, it does one of two things.

One is, it puts a greater emphasis on unscripted live events. Because that will command a real-time audience. And then the scripted shows tend to be much more selective. And of course the PDR allows them to skip or speed past the apps.

EA: Well, I'm really kind of saying more than that. I'm saying that as a scripted show, you want the DVR. You're getting a 13 per cent uplift because of the DVR. There's not happening in the unscripted show. But the real point I'm trying to make is the DVR phenomenon has been hitting in the last couple of years and its become so much a part of our lives that we are actually able to discern usage patterns already.

The people that measure television viewerships have gotten together and redefined ways they're going to measure DVR usage. That data has just come out.

I just relayed to you opinions or trends that have literally just been noticed with the fall television season. This is October 4th. That's the power of what I'm trying to say as an example. Going back to my main point - because your question was on the drivers of all of this.

The legacy businesses' revenues are going down. The profits are going down. The numbers on the digital side in terms of viewing, anyway, are - if they're not going through the roof, they're growing at 20-40 to 50-80 per cent. They're not necessarily replacing all the revenues on the digital side that they're losing on the legacy side. The fact is, they're still trying to figure out the business model.

I'm just saying in looking at this, fundamentally, there are Tectonic shifts in the business. When legacy businesses start to head south - as in general most of them are, even in the book-publishing industry and the education area... The price increases and the increase in volume has been a nice environment for book publishers' education for years and years.

But in the last eight months, those are beginning to top off and go down. That's the underpinning that's causing this in terms of people trying to really focus on the online way, and how to make money in that space. And what the online consumer wants. You must deal with the consumer. You cannot deal with the intermediary B2B.

It's the NBC studios and the Newscorp that's coming out with [Hulu]. It's not the network NBC. The network NBC already has NBC.com. It's talking about the actual studio itself that's coming out with something to deal directly with the consumer.

AN: Anand Narayanan here. If I may add a couple of points to what Ed said... if you take a step back and look at what's fundamentally changed or what's fundamentally affected the industry, and why consumer behavior patterns are changing... it's at a very, very broad level and an industry level.

The proliferation of broadband in households... Be it the hockey stick phenomenon by which it's steadily increasing and comprising all households... And the increasing width occupied within the house. Making it therefore easier and easier to push rich content and rich experiences through it.

The consumer electronic devices. Getting proliferated in larger numbers. Way more capable devices. The fact that storage prices keep going down means more and more things are possible on tinier devices.

This combined with the fact that the internet pipe is becoming larger in households. And with the economy that was doing very well over the last few years, people had more money to spend on things. People had more time to spend on a better experience. They bought a lot of these devices. The need for richer experience, therefore, started developing.

That's when they started looking out for content. That's when they started out demanding content from the content companies. That's how this whole chain of content companies having to respond started really wheeling away.

It's been a virtuous cycle since then of one change leading to another. Thus, leading to the fragmentation of experiences, leading on to the content companies reacting, leading on to 
phenomenon like YouTubes happening and so forth.

This leads on to what Ed then said about DDRs and people wanting to watch scripted shows when they want rather than when the broadcasters want them to.

MM: Great. Anything else along those lines? SPM: This is Sherra Pierre March. I just wanted to add a couple of things. Agreed, agreed, agreed. What's interesting about this whole moment in time, I think, is the notion of this aggregation model. What's interesting here is that this demographic that...

What's interesting here is the demographics that you speak to. This younger generation. What's interesting to me is that they are aggregating, because they now have spent the last 2, 3 or 4 years really accessing content on demand in their own way. Right?

They've supported their own peer-to-peer networks in ways that our generation... We're still even trying to understand what those peerto-peers look like.

But what's interesting to me is that they are now aggregating content as a way of life in their heads. Faster than technology companies or media companies can create the devices. So they are pushing at us in all sorts of ways.

I see that there will be an interesting dynamic in terms of the hardware that hits the household. And how consumers will demand the fact that I want this hardware.

So let's take, for example, the set-top boxes that we've mentioned. The TiVos. Or the Cable \& Satellite boxes. Or the IPTV boxes that hit the households. It will be interesting to see how the consumers' demand for integration of that hardware. They will also demand to pick up a movie from their TiVo, and continue to look at it on their iPhone.

They will also demand that they do not require a TiVo for every room, but a device that will aggregate the content for them, based on the room that they're in and the mood that they're in. They'll also require that the device through maybe smart cards will understand their spending behaviors and will understand their credit card information already. They'll understand where they live. Et cetera.

It's going to be very, very interesting. The rush for standards. And I don't know what these standards look like in this world. I know that I will not end up with a TiVo digital set-top box and an IPTV box in my house. I know there's going to have to be some solution for that.

I think there's a race that's on, and I think it's a very interesting race. I think that we are trying to catch up with that demographic. And I would say that that's probably more of a US reality than it is a reality in Asia.

MM: Sherra, this might be a great place to start summarizing around some more forwardlooking comments around the digital home or the digital cinema, as indicators or harbingers of the future.

EA: It's Ed Altman. Let me make some comments.

Yesterday I was in Santa Clara, attending Clarks Associates Digital Home Conference. I'm rather full of a variety of data - a humongous amount of data.

Here are some of the things that came out of it, in terms of the digital home and what's beginning to emerge. It ties perfectly into what Sherra was just saying.

Ironically, it's not as if Sherra and I prepared together for this call.

One of the emerging needs in the digital home are two things. One is for a service provider to provide two different services. One is security. People are very concerned and would be open to somebody being sure that as they select things on their TiVo or PC or whatever, that information isn't identified with them as an individual.

Also, just security from the point of view that that guy can't get it and know that perhaps I watch TV channels at 2 in the morning that I wouldn't want other people to know.

The other thing that's coming out is the need for a full-service maintenance capability in the home. Sherra just said the need... If you have a DVR and I have four televisions, I want tomorrow DVR capability on four televisions. I want to know that I can integrate my PC, if I put that communications link between a $\mathrm{PC}$ in my house to a television. That it's going to apply to all the PCs and televisions in the house.

I want to know that some company is going to maintain that.

A key part of Verizon's and AT\&T's strategy is what they're calling an RG - a residential gateway. In that whatever device it is that they're putting in the home, that top box, PC or 
whatever... That they then will enable me to manage my whole network — whether it's a wired or wireless network. And as a consumer, I'm going to be more and more making buying decisions from the consumer home perspective for a service provider that can provide me the security and maintenance support for all my devices.

So that every time my PC changes, I don't need to go out and upgrade the microcode or the Windows Vista. I want somebody else to do it.

From a consumer point of view, these are two very fast-emerging things. People realize that if this stuff is down, they can't lead their lives. They're also realizing that they don't always have the technical ability to do it.

Even if they have the technical ability, they want to lead their lives. They don't want to take time to upgrade their computer environment in their home. That's one very key emerging trend. MM: Cool.

SP: This is Shrikant Pathak from Mumbai.

Michael, since you asked about digital cinema and digital home as two different things. Is that correct?

MM: Yes.

SP: This is a comment related to digital cinema. And this is a comment which actually relates to our part of the world, in some ways. I don't know how much of it is applicable there.

But I see between the two that purely digital cinema is something that's likely to move forward much faster. It has a tangible ROI for producers and publishers and marketers and distributors. And it has something which has an impeccable appeal as far as the consumers and users are concerned.

The traditional film-based distribution takes time. It costs a lot more money as far as the producers and distributors are concerned. Therefore, it has an impact on what revenues they generate.

Not only that, but it also has an impact from a piracy perspective. The longer it takes to reach the audiences all across, the greater the chances that they'll have pirated stuff off to them faster than you will.

So in this part of the world, we see digital cinema...

MM: When you say, "In this part of the world," do you mean specifically in Indian subcontinent? SP: Yes.
MM: And do you mean in the mediaentertainment industry.

The film-production industry. And in terms of the number of films we produce, it's probably the largest in the world. It is a large industry, here. Not in dollar terms, but at least in the number terms.

MM: So if I understand you right, you're saying that digital cinema really as an idea and as a development has really taken hold in India, as well as in particular because of the robustness of the Indian film/entertainment business.

SP: And the ability to distribute it digitally much faster than you would with a film-based distribution.

MM: Right.

The key point that you've made there is that by accelerating the propagation of an entertainment time-to-market... Accelerating time-to-market... You thereby eliminate windows of opportunity for pirates to misuse or to steal a property.

SP: Absolutely. Yes.

MM: Yes.

EA: This is Ed Altman.

An amazing discussion in the class yesterday to this point has to do with digital cinema. The digital home. The day-and-date. The windows of the content. Primarily Hollywood. But all of the content companies to one degree or another use it to make money.

The premium when you first get a piece of content. But that in India and in other places, the digital cinema. More and more people are going to theatres, and they don't necessarily have the infrastructure in the home. Whether the infrastructure is a PC or Adobe Digital sound system or a high-def sound system is becoming more and more prevalent and seem to become almost standard in the US... While in the US, the number of people going to movie theatres is beginning to wane... They clearly said that within another three or four months, you're going to see Comcast, Time-Warner and the MSOs in this country - with the support of the studios have day and date for a DVD release.

So it's still out in the future, but a movie will be released at your local theatre at the same time it is in your home. But then as soon as Wal-Mart gets the DVD, Comcast is going to be showing that movie at your home. 
It might be a $\$ 30$ or $\$ 40$ VOD download, but that's coming in a matter of months. And just because there's more of a cocooning effect in the US - the fact that people just have invested more in HD televisions and they have these nice environments in their home, and more couches or whatever around the nice televisions or the Dolby Digital Sound Systems - that's going to be happening in a matter of months.

That's not going to make Wal-Mart happy with their DVD sales are going to perhaps be impacted because of a $\$ 30$ or 40 option on every Tuesday when those DVDs come out, that you could watch the movie at home.

Also, what's going to help the DVD distribution is the whole [long tail] and burning DVDs. So very soon, I'm going to be able to go in to Wal-Mart and not just buy a DVD that's... I don't know how many DVDs Wal-Mart has on the shelves, but I'll guess 3,000 or 4,000 or 2,000 . I don't know.

But if I go in to Wal-Mart and there's a DVD burner and there's a catalogue of 1 million movies that I could just make an order for and get them all on one DVD or six DVDs, that may take 6-15 min to burn it - but I put in my order and Wal-Mart's happy. Now I have 10 or 15 more minutes to shop around Wal-Mart.

I come back and I pick up my DVDs. That's a long tail. You don't have to handle the replenishment. You don't have the supply chain issue. This is the digital supply chain. Not the physical supply chain. That's going to be happening in another 8-10 months.
So with all that we've seen - what's about to occur is just going to be that much more dramatic than what's already occurred today. AN: If I may add, this is Anand here... If you look at it purely from the consumer's perspective... The coming generation would be called the digitally connected generation. With the internet as the heart or brain - The invisible thread that holds all of this together, and enables the different functions. The nodes would be where the experience meets the consumer — which would be the home, the office, the car, et cetera.

The back-end infrastructure would be the devices. Which, as we know, are becoming more and more capable. The enablers would have to be the actual consumers, themselves. By "consumers," I mean a broad term. As the line between who's producing content and who's distributing it and who's consuming it keeps growing thinner by the day.

Today the consumer is also the producer. The producer is also the consumer, and so forth. And the suppliers through this whole ecosystem would be the different distributors. Again, more on a conceptual level.

They would be based where it's contextually relevant. Someone who's a distributor to a party in the value chain would be an aggregator to another party. They'd be a producer to another party and a consumer to a third party and so forth. So from a vision perspective, I believe this is how the whole industry or the ecosystem is evolving from a consumer's perspective.

MM: Great. That sounds like a perfect place to end.

Copyright in the content of this article resides with Tata Consultancy Services Ltd. 